\title{
Resenha de "Teorias do Discurso - Novas Práticas e Formas Discursivas"
}

\author{
A review of "Teorias do Discurso - Novas Práticas e Formas Discursivas"
}

\author{
Douglas Ribeiro de Moura ${ }^{1}$ \\ Universidade Federal de Viçosa - UFV \\ douglasrmoura@gmail.com
}

O livro Teorias do discurso - novas práticas e formas discursivas, lançado no primeiro semestre de 2020 e organizado por três docentes da Faculdade de Letras da Universidade Federal de Minas Gerais: Wander Emediato, Ida Lucia Machado e Glaucia Muniz Proença Lara, é fundamental para aqueles que buscam conhecer as principais abordagens, teorias e metodologias que compõem os estudos discursivos.

A obra, constituída de uma apresentação e de 10 capítulos, entretanto, não esgota as possibilidades de pesquisa propiciadas pela Análise do Discurso. Nesse sentido, os organizadores irão afirmar que "a AD sempre foi uma disciplina ousada" (p. 10) e que "tem conseguido ser única e, paradoxalmente, múltipla” (p. 12) graças a seu caráter interdisciplinar e à sua capacidade de desenvolver quadros teóricos e instrumentos analíticos próprios. Assim, ressalta-se que o livro é um complemento - necessário - a outros trabalhos, que poderão ser mais ou menos aprofundados em uma ou em outra abordagem apresentada.

A linguagem utilizada pelos autores é ponto que merece destaque: além da clareza na escrita, os capítulos apresentam uma estrutura lógica e acessível para a compreensão dos conceitos. O uso adequado e pertinente de análises práticas faz com que a assimilação dos conteúdos seja simples, mesmo nos casos em que os leitores desconheçam a temática discutida. Informações complementares e referências bibliográficas também podem ser encontradas ao longo dos tópicos, o que igualmente favorece os estudantes que buscam textos-base.

Vale ressaltar que a própria sequência dos capítulos é apropriada: já no primeiro, Wander Emediato apresenta um panorama geral dos estudos discursivos, dividindo-os em três gerações e propondo um modelo de análise integrada: a primeira, de tendência representacional; a segunda, de tendência enunciativa e pragmática; e a terceira, de tendência sociocognitiva. Os capítulos seguintes irão apresentar e trabalhar as teorias exibidas pelo autor nesse fragmento inicial.

\footnotetext{
${ }^{1}$ Mestre em Letras - área de Estudos do Texto e do Discurso pela Universidade Federal de Viçosa.
} 
O segundo capítulo é de autoria da professora Ida Lucia Machado. Nele, o fenômeno da resiliência é abordado a partir da articulação entre a Teoria Semiolinguística e as Narrativas de Vida. Utilizando o exemplo de Lázaro Ramos no livro Na Minha Pele, a autora mostra brilhantemente como a noção de sujeito e a própria Semiolinguística de Charaudeau precisaram resistir para se consolidarem no âmbito dos estudos discursivos, superando as desconfianças e os obstáculos iniciais.

O terceiro capítulo é da também organizadora Glaucia Muniz Proença Lara e se debruça sobre a Semântica Global de Dominique Maingueneau. A análise que a autora empreende merece elogios, pois cada um dos planos discursivos da referida Semântica intertextualidade, vocabulário, temas, estatutos, dêixis enunciativa, modo de enunciação e modo de coesão - é didaticamente detalhado para os leitores.

Hugo Mari e Paulo Henrique Mendes refletem, no quarto capítulo, a respeito de alguns dos marcos que contribuíram para o desenvolvimento de diferentes abordagens da AD. São destacados os aportes de Adam Schaff, Ludwig Wittgenstein, John Austin, John Searle, Roman Jakobson e, mais recentemente, Eliseo Verón. Todas as considerações dos autores são exemplificadas por meio de noções e de raciocínios empreendidos em teorias discursivas.

No quinto capítulo, Cairo Joseph dos Santos Ferreira e Grenissa Bonvino Stafuzza utilizam conceitos provenientes de Bakhtin e do Círculo Russo para analisar trechos do livro Divergente, de Veronica Roth, à luz da verbovocovisualidade, demonstrando como tal teoria pode ser aplicada à literatura e concluindo que, para essa corrente de pensamento, a linguagem é verbovocovisual per se.

Luciano Magnoni Tocaia busca, no sexto capítulo, estabelecer diálogos entre a AD de linha francesa e a Semiótica Discursiva de Greimas. Para tanto, apresenta as noções de formação discursiva e de formação ideológica, bem como de tematização e de figurativização. A análise - bastante interessante - se dá sobre capas do jornal francês Minute e exemplifica como tais abordagens podem ser combinadas visando a uma compreensão mais ampla de como operam e se manifestam os discursos intolerantes e preconceituosos.

No sétimo capítulo, é a Análise de Discurso Crítica que ganha destaque. Nele, as professoras Maria Carmen Aires Gomes e Viviane Cristina Vieira apresentam conceitoschave para essa abordagem: discurso, poder, ideologia e texto, além de tratarem da expansão dos estudos discursivos críticos no Brasil e na América Latina. É importante ressaltar que a teoria pesquisada por essas autoras direciona as atenções para questões de desigualdades sociais, injustiças, relações de poder e dominações, motivo pelo qual é tão interessante de ser estudada e cujas bases estão muito bem descritas por Gomes e Vieira. 
O Modelo de Análise Modular do Discurso, apresentado e exemplificado por Gustavo Ximenes Cunha no oitavo capítulo, mostra-se extenso, uma vez que analisa os discursos a partir de três dimensões: linguística, textual e situacional. Por meio da análise de trechos de uma audiência judicial envolvendo violência doméstica, o autor demonstra, de maneira simples e objetiva, que os analistas do discurso podem realizar um trabalho amplo sem deixar de lado cada uma de suas circunstâncias.

O nono capítulo é especialmente interessante e proveitoso: Roberto Leiser Baronas e Julia Lourenço Costa problematizam a repetitiva aproximação entre as noções de discurso e de formação discursiva propostas por Michel Foucault e Michel Pêcheux. Por meio de uma extensa revisão teórica, os autores defendem a tese de que as separações aí existentes se dão porque as bases epistemológicas dos teóricos franceses são diferentes. Trata-se de um texto instigante, ainda que a ideia central, como afirmam os próprios escritores, necessite ser desenvolvida de maneira mais extensa.

Por fim, o décimo capítulo, de autoria da professora Maria Antonieta Amarante de Mendonça Cohen, debate as relações existentes entre a psicanálise e a linguagem. A principal - e intrigante - conclusão a que se chega é que a mentira é utilizada nas sessões psicanalíticas como um tipo de argumentação voltada à construção de um ethos por parte dos pacientes em relação a seus analistas.

Como se observa, toda a obra é de leitura essencial para aqueles que se interessam pelo discurso e por suas numerosas linhas de pesquisa. Por se tratar de um livro em que várias abordagens são apresentadas, recomenda-se sua inserção entre as bibliografias básicas de cursos e disciplinas introdutórias sobre a Análise do Discurso, ainda mais levando-se em conta a simplicidade da escrita. De fato, é um trabalho que merece reconhecimento a seus autores e organizadores.

\section{Referência}

EMEDIATO, Wander; MACHADO, Ida Lucia; LARA, Glaucia Muniz Proença (Org.). Teorias do discurso - novas práticas e formas discursivas. Campinas, SP: Pontes Editores, 2020. 268p. 